\title{
Women Feeling Before, During and After ammography: Egyptian Context
}

\author{
Salwa Hagag Abdelaziz* \\ Medical Surgical Nursing, Cairo University, Egypt
}

Submission: December 08, 2017; Published: March 15, 2018

*Corresponding author: Salwa Hagag Abdelaziz, Medical Surgical Nursing, Faculty of Nursing, Cairo University, Egypt, Email: Nadakimo2005@yahoo.com/Shagag2005@cu.edu.eg

\begin{abstract}
A descriptive analytical design was carried out to provide a snapshot of women feeling before, during and after mammography. A convenience sample of 400 women was utilized and all eligible participants admitted to the Women Imaging Unit who were 40 years of age or above, attended mammography screening with no symptoms. A structured questionnaire was developed by the researchers and contains two parts; Socio-demographic data and women feeling before, during and after mammogram. The study results revealed that the majority of women under the study (78\%) expressed fear regarding mammography results and comfort feeling toward technologists (83.5\%). And 69\% of women expressed feeling of shame during mammography procedures. $97 \%$ of women expressed cooperation from technologists while the majority (86.2\%) expressed feeling of pain during breast compression. New guidelines should be established for nurses and technologists in supporting and encouraging encourage women attending mammogram without feeling of fear and shame of the procedures. The clinical studies in US, Sweden, and Netherlands have suggested that deaths from breast cancer could be cut by between $36 \%$ and $44 \%$ if mammographic screening were performed annually on all women above 40 years [1].
\end{abstract}

\section{Introduction}

It is mentioned in the literature that during mammography, the technologist will position the patient and image each breast separately. One at a time, each breast is carefully positioned on a special film cassette and then gently compressed with a paddle (often made of clear Plexiglas or other plastic). This compression flattens the breast so that the maximum amount of tissue can be imaged and examined [2]. This compression causes uncomfortable feeling during the mammography technique. Several studies over the last 20 years have reported that some women do find mammograms to be uncomfortable and sometimes painful, a number of factors that influence a woman's comfort level during mammography including; Breast compression; Friendliness and sensitivity of the mammography technologist(s), facility atmosphere and procedures. So, there are many suggestions on how to minimize discomfort during mammography and how to alleviate much of the pain during mammography such as: Find a "friendly" mammography facility with knowledgeable mammography technologists or nurses; Control the breast compression themselves during mammography; Change mammography facilities when dissatisfied with care/service; Use calming self-statements and learn distraction techniques to use during mammography [3].

It is stated in the literature that some mammography facilities will allow the patient to control the breast compression herself during mammography. This can greatly reduce anxiety, making the woman feel more comfortable during the procedure, both physically and emotionally. Women should feel free to ask the technologist about controlling breast compression themselves when scheduling the exam or before the exam begins [4]. So the technologist skill is essential element during the mammogram. Researchers have found that a woman often feels more comfortable during a mammogram with a courteous technologist who can provide thoughtful answers to her questions. Knowledgeable technologists can also help women with distraction techniques to take their minds off the exam. Researchers also found that factors associated with mammogram discomfort included the facility itself, satisfaction with care, and the patient's perception of the technologist's "roughness" [5]. Clinical studies reported that patients should feel firm pressure during mammogram due to compression but no significant pain. Patients who feel pain should inform the technologist so that the breast may be repositioned. Women who have sensitive breasts may wish to schedule their mammograms at times of the month when the breasts are less tender [6]. In general, the week before and during menstruation is when breasts are most tender, and the week after the menstrual cycle is when breasts are least tender. Also, the day of the mammography examination nurses should instruct women about not applying deodorants, antiperspirants, powders, lotions, creams, or perfumes under arm or on the breast because it could be visible on mammogram and cause confusion. In addition the amount of breast tissue a woman has does not affect her risk of 
developing breast cancer [1]. As regards to patient's Cooperation, It is also important that the patient be fully informed about each step of the mammogram procedure to ensure that she can fully participate and cooperate in the exam. During the actual x-ray exposure, patients must remain absolutely still and hold their breath to eliminate image blurring due to patient motion. Women are encouraged to take a few moments prior to the exam to talk to the mammography technologist about any questions or concerns [4].

Bailey [7] concluded that nurses have a vital role to play in encouraging women to become more breasts aware. Their health promotion activities in this area can have an important impact on the uptake of breast screening initiatives. Nurse practitioners have important role in primary and secondary prevention of breast cancer because their holistic perspective and advanced practice skills enable them to intervene for clients at all levels of health care. Nurses were identified as desired sources of information and support as well as reassure women during mammogram. Over $80 \%$ of women stated that they would like some or a lot of information and support from specialist nurses [8]. So, all level of practitioners (Nurses, technologists, physician, social worker, and physiotherapist) must continue to encourage women about screening practices and simplicity of the procedures. Above all interdisciplinary screening team with competent skills in mammogram should be available in radio-diagnosis department to encourage and support women, before during and after mammogram [9]. Therefore; the purpose of this study is to identify women feeling before, during and after mammogram.

\section{Material and Methods}

The aim of this study was to identify women feeling before, during and after mammography

Design: Descriptive analytical design was utilized to conduct the current study. This design is frequently used to collect detailed description of the phenomena being studies for further improvement in the outcomes.

Setting of the Study: The study was conducted at El Manial University Hospital (Women's Imaging Unit, Radiology department).

Sample: A convenient sample of 400 adult women coming for screening mammography. Their age above 40 years, one week after menstrual cycle and no breast complain.

Tools: Structured questionnaire has been developed, constructed by researcher, tested and validated by expertise in the field of radiodiagnosis and nursing.

a) The first part consists of sociodemographic data to elicit subject's age, marital status, residence, occupation and educational level.

b) The second part consists of 8 items before, during and after mammography. Before; such as fear of the result and comfort feeling regarding technologist. During; feeling of shame, feeling of pain during compression, cooperation from technologist and any explanation regarding procedures. After; knowing result immediately and any explanation regarding mammography results \& follow up.

Pilot Study: A pilot study was conducted on 10 women to assess clarity and objectivity of the questionnaires. The pilot study also revealed data about the readiness of women above 40 years to undergo screening and be included in the study.

\section{Procedures}

Once the official permission was obtained from the head of the department, the researcher initiated data collection. Women who met the inclusion criteria were included in the study from El-Manial University Hospital. Researcher met the women before mammography screening. Initially, the purpose and the nature of the study were explained. The researcher emphasized to the women that participation in the study is voluntary and the anonymity and confidentiality of their responses were strictly assured. Researcher attended the mammography procedures with all women and interviewed them after mammography procedures.

\section{Analysis of Data}

SPSS was used to analyze the data. Descriptive statistics such as frequency, percentage distribution, mean and standard deviation were used.

\section{Results}

As shown in Table 1, the socioemographic data of the present study among women included age, marital status, occupation and level of education. As regards age, all women under the study above 40 years ranged between (40-73). A high percentage of women's age (66.25\%) ranged between $40-<50$ years followed by $(28.75 \%)$ from $50-<60$ and $(4.25 \%)$ from $60 \leq 70$ and the rest of women above 70 years with a mean age $46.93 \pm 6.47$. As regards marital status, the majority of women (80\%) were married while the minority $(3.75 \%)$ was single. As regards occupation, house wife was the highest percentage while the lowest percentage related to employee from Cairo University ( $85.25 \%$ and $4.25 \%$ respectively). Regarding to level of education a relatively high percentage of women were can not read and write as well as secondary school $(36.25 \%$ and $28 \%$ respectively). While the minority of them (5.75\%) have postgraduate education.

Table 1: Frequency and percentage distribution of Sociodemographic Characteristics among study sample.

\begin{tabular}{|c|c|c|}
\hline Variables & \multicolumn{2}{|c|}{$\mathbf{n = 4 0 0}$} \\
\hline Age years & No & $\%$ \\
\hline $40-$ & 265 & 66.25 \\
\hline $50-$ & 115 & 28.75 \\
\hline $60-$ & 17 & 4.25 \\
\hline $70-$ & 3 & 0.75 \\
\hline Mean \pm SD & \multicolumn{2}{|c|}{$46.93 \pm 6.47$} \\
\hline
\end{tabular}




\begin{tabular}{|c|c|c|}
\hline Marital Status & No & \% \\
\hline Single & 15 & 3.75 \\
\hline Married & 320 & 80 \\
\hline Divorced and Widowed & 65 & 16.25 \\
\hline Occupation & No & \% \\
\hline Employee & 17 & 4.25 \\
\hline Clerical & 64 & 16 \\
\hline Workers & 54 & 13.5 \\
\hline Housewife & 233 & 58.25 \\
\hline Nurses & 32 & 8 \\
\hline Level of Education & No & \% \\
\hline Cannot read and write & 145 & 36.25 \\
\hline Primary and preparatory & 85 & 21.25 \\
\hline Secondary & 112 & 28 \\
\hline University & 35 & 8.75 \\
\hline Post graduate & 23 & 5.75 \\
\hline
\end{tabular}

As shown in Table 2 the majority of women under the study $78 \%$ expressed fear regarding results of mammography. As regards comfort feeling to technologist, 334 women under the study which represent (83.5\%) expressed comfort feeling while $(16.5 \%)$ had no comfort feeling to technologist. It is apparent from Table 3 that $(69 \%)$ of women feeling of shame during mammography procedure while (31\%) didn't feel shame. Concerning any explanation regarding technique, the same table represents that $(12.75 \%)$ of women asked questions regarding to frequency of mammography and effect of radiation $(11.75 \%$ and $1 \%$ respectively). Regarding to technologist's cooperation, most of women under the study $(97.7 \%)$ expressed that there was cooperation and explanation from technologist during procedure while the minority (3\%) expressed no cooperation. According to pain during breast compression, the same table revealed that the majority of women $(86.2 \%)$ were feeling of pain in the form of mild, moderate and severe $(28.25 \%, 49.75 \%$ and $8.25 \%$ respectively) while $(13.75 \%)$ had no pain during breast compression. Table 4 shows that the majority of women (99.25\%) known results immediately after mammography and their questions answered immediately from technologist as well as radiologist while the minority $(0.75 \%)$ didn't know results immediately. As regards follow up (18\%) of women asked about follow up of mammography and (82\%) not asked.

Table 2: Frequency and Percentage Distribution relate to women's before mammography.

\begin{tabular}{|c|c|c|}
\hline \multirow{2}{*}{ Variables } & No & n=400 \\
\cline { 2 - 3 } & \multicolumn{2}{|c|}{ Fear Regarding Results } \\
\hline \multicolumn{3}{|c|}{} \\
\hline No & 88 & 22 \\
\hline Yes & 312 & 78 \\
\hline \multicolumn{2}{|c|}{ Comfort Feeling to Technologis } \\
\hline No & 66 & 16.5 \\
\hline Yes & 334 & 83.5 \\
\hline
\end{tabular}

Table 3: Frequency and Percentage Distribution related to women's during mammography.

\begin{tabular}{|c|c|c|}
\hline \multirow{2}{*}{ Variables } & \multicolumn{2}{|c|}{$\mathrm{n}=\mathbf{4 0 0}$} \\
\hline & $\%$ & No \\
\hline \multicolumn{3}{|c|}{ Fear Regarding Results } \\
\hline No & 124 & 31 \\
\hline Yes & 276 & 69 \\
\hline \multicolumn{3}{|c|}{ Any explanation regarding technique } \\
\hline No & 349 & 87.25 \\
\hline Yes( among yes response) & 51 & 12.75 \\
\hline Frequency of mammography & 47 & 11.75 \\
\hline Effect of radiation & 4 & 1 \\
\hline \multicolumn{3}{|c|}{ Technologist cooperation and explanation regarding technique } \\
\hline No & 12 & 3 \\
\hline Yes & 388 & 97 \\
\hline \multicolumn{3}{|c|}{ Feeling of pain during breast compression } \\
\hline No & 55 & 13.75 \\
\hline Yes(among yes response) & 345 & 86.2 \\
\hline Mild & 113 & 28.25 \\
\hline Moderate & 199 & 49.75 \\
\hline Severe & 33 & 8.25 \\
\hline
\end{tabular}

Table 4: Frequency and percentage Distribution related to women's after mammography.

\begin{tabular}{|c|c|c|}
\hline \multirow{2}{*}{ Items } & No & $\mathbf{n}=\mathbf{4 0 0}$ \\
\cline { 2 - 3 } & $\begin{array}{c}\text { Knowing results immediately and any explanation be answered } \\
\text { from technologist and radiologist }\end{array}$ \\
\hline No & 3 & 0.75 \\
\hline Yes & 397 & 99.25 \\
\hline Any explanation from women regarding follow up \\
\hline No & 328 & 82 \\
\hline Yes & 72 & 18 \\
\hline
\end{tabular}

\section{Discussion}

Breast cancer is by far the most common malignancy among women worldwide, and $41 \%$ of all new cases are diagnosed in developing countries, furthermore, as the population increases and age, the number of new cases in these countries is expected to increase dramatically [10]. Nurses have an important role in early detection of breast cancer and supporting women during screening mammography. So, when the role of the nurse is explicitly identified, further studies can begin to determine the effectiveness of nursing practice in terms of women health regarding regular mammogram. As regards age, all women under the study above forty years ranged between 40 to above 70 years with a mean $46.9+6.47$. The results are in agreement with who stated that getting older than forty years is considered risk factors 
for breast cancer that can't be altered [11]. A study conducted by Hopwood [12] who mentioned that the incidence of breast cancer rises between age $45-55$ then it begins to rise again quite sharply.

Regarding to occupation and level of education a relatively high percentage of women under the study were housewife. Concerning level of education, a high percentage was for can not read and write followed by primary and the either secondary, university as well as postgraduate. So, most of women need health education and better knowledge about mammography screening regarding importance of follow up. Leslie [13] Stated that some educated women failed to practice breast cancer screening according to guidelines. It is observed in the current study that educated women had knowledge deficit about screening guidelines. So, it is important to reinforce Screening practices among all levels. The results revealed that most of women under the study expressed fear regarding results. This finding is consistent with Dibble [14] who tested barrier to mammography and concluded that worry about results is considered one barrier for women regarding mammography. Regarding to the response feeling of clients (women) toward technologist, the study results showed that the majority of women feeling of security and comfort to technologist By the way, Researchers conducted mammography technique for all women under the study, this may clarify the importance of nurse's role during procedure in order to grasp women's attention during procedures by using calm statements.

In this respect Leslie [13] stated that some women do find mammography to be uncomfortable due to friendliness and sensitivity of the mammography technologists. So, it is very important for technologists to deal friendly with women during mammography and enhancing knowledge regarding using calming self statement and learn distraction technique to use during mammography. Regarding to women during mammography the current study revealed that the highest percentage of women expressed feeling of shame during the procedure. Concerning explanation regarding technique, the majority of women didn't ask any question related to technique and expressed that this is new technique and this is the first time they heard about it. While the rest of sample asked question related to frequency of mammography and effect of radiation. In relation to technologist's cooperation and explanation regarding technique, most of women under the study expressed cooperation from technologist while the minority expressed the opposite. This finding is supported by Dibble [14] who reported that embarrassment, unpleasantness of procedure and lack of privacy are barriers to mammography. Anthony [15] added that the setting for conducting mammography should be peaceful with some kind of beauty. It should be hospitable and warm. Each woman should feel that she is unique and important as a member of our family. It should be emphasized that peace of mind will be granted to the women who have a normal mammography. Women should informed that health care providers are not just looking for early lesions, but providing peace of mind to the women with a benign mammography. Concerning these points the researcher have to emphasis on training staff to be attentive and gentle to the women, to answer carefully all questions asked intelligently.

As regards feeling of pain during breast compression. The current results revealed that the majority of women under the study expressed feeling of pain, among those, the higher number expressed moderate pain followed by mild and severe. In this respect American Cancer Society [4] reported that breast compression may cause some discomfort, women should feel firm pressure during procedures but no significant pain. In relation to knowing results after mammography, the study results revealed that most women under the study known immediately the result while the minority didn't know because radiologists were very busy. Most of women expressed that their explanation answered from technologist and radiologist. Also, the results found that the majority of women didn't ask about follow up while the rest asked about it in order to perform it. There is no research was carried out in order to support or contradict these points. Regarding to technologist's knowledge and skills in mammography. The results of the present study revealed that all technologists under the study not considered mammography as a routine work and required skills, the majority of them mentioned that being a women is important while the rest stated that having experience and be patience with women during the procedures. Also, all of them agreed that communication is important during mammography and help in grasping women attention for reassurance. Study conducted by Anthony [15] highlighted that communication skills based on love and sincerity need to be developed. So, it is important for the nurse to be involved in this field in order to obtain tangible results because every life saved is a real success. To summarize, nurses play a significant role in providing women with support and reassurance during mammography. Women's imaging Unit lack staff of nurses who are able to spread awareness regarding screening practices and safe procedure of mammogram. Further research need to be conducted to explore technologists' role in supporting women during mammogram. Special training program included special skills and guidelines should be conducted for technologist in Women Imaging Unit.

\section{References}

1. Myo Foundation for Medical Education and Research (2016).

2. Mitchell AJ, Pereira IE, Yadegarfar M, Pepereke S, Mugadza V, et al. (2014) Breast cancer screening in women with mental illness: comparative meta-analysis of mammography uptake. Br J Psychiatry 205(6): 428-435

3. Kirubakaran R, Chee Jia T, Mahamad Aris N (2017) Awareness of Breast Cancer among Surgical Patients in a Tertiary Hospital in Malaysia. Asian Pac J Cancer Prev 18(1): 115-120.

4. (2017) American Cancer Society.

5. (2006) American Cancer Society.

6. Agasthya GA, D'Orsi E, Kim YJ, Handa P, Ho CP, et al. (2017) Can Breast Compression Be Reduced in Digital Mammography and Breast Tomosynthesis? AJR Am J Roentgenol 209(5): W322-W332.

7. Bailey $\mathrm{K}(2000)$ The nurse role in promoting breast awareness. Nurs Stand 14 (30): 34-36. 
8. Chalmers K, Thomson K, Degner LF (2001) Information support and communication needs of women with a family history of breast cancer. Cancer Nurs 19(4): 204-213.

9. Abdelaziz S, Youssef N, Hassan N, Abdelrahman R (2015) Factors Associated with Mammography Screening Behaviors: A crosssectional Descriptive Study of Egyptian Women. International Journa of Medical, Health, Biomedical and Pharmaceutical Engineering 9(5).

10. (2004) National Cancer Institute (NCI).

11. Linton A, Maelius N (2003) Introduction to medical surgical nursing ( $3^{\text {rd }}$ edn.), Saunders Company, Philadelphia, USA.

This work is licensed under Creative

Commons Attribution 4.0 License

DOI: 10.19080/JOJNHC.2018.06.555697
12. Hopwood P (2004) Western lifestyle and breast cancer risk ( $4^{\text {th }}$ edn.), Eurepean breast cancer conference. European Breast Cancer Coalition, Italy.

13. Leslie NS, Deiriggi P, Gross S, DuRant E, Smith C (2003) Knowledge, attitudes \& practice surrounding breast cancer screening in educated Appalachian women. Oncol Nurs Forum 30(4): 659-667.

14. Dibble SL, Roberts SA (2003) Improving cancer screening among Lesbians over 50: Results of a pilot study. Oncol Nurs Forum 30(4): E71-E79.

15. Anthony BC (2003) Overcoming obstacles in implementing breast services locally ( $6^{\text {th }}$ edn.), Europa Donna Conference, Italy.

\section{Your next submission with Juniper Publishers will reach you the below assets}

- Quality Editorial service

- Swift Peer Review

- Reprints availability

- E-prints Service

- Manuscript Podcast for convenient understanding

- Global attainment for your research

- Manuscript accessibility in different formats

( Pdf, E-pub, Full Text, Audio)

- Unceasing customer service

Track the below URL for one-step submission https://juniperpublishers.com/online-submission.php 